\title{
Big Data Analytics Implications for Smart Tourism Destinations Towards the Enrichment of Content Tourism
}

\author{
N. Padmaja ${ }^{1}$ and T. Sudha ${ }^{2}$ \\ ${ }^{1 \& 2}$ Department of Computer Science and Engineering, \\ School of Engineering and Technology, Sri Padmavati Mahila Visva Vidyalayam, Tirupati, Andhra Pradesh, India \\ E-Mail: gowripadma@yahoo.com, thatimakula-sudha@yahoo.com
}

\begin{abstract}
Smart tourism has huge amount of Social Big data available from tourists can cherish the value conception process for a Smart Tourism Destination. Applying a multiplecase study analysis, a set of regional tourist experiences related and destination, to derive patterns and opportunities of value creation generated by Big Data in tourism. Near conclusions and data in terms of improving decision making, creating marketing strategies with more personalized offerings, transparency and trust in dialogue with customers and stakeholders, and emergence of new business models, exploitation of Big Data in the context of information-intensive industries and mainly in Tourism. Smart Tourism Destination today is the front line of study in the tourism field and is a promising area from various research perspectives in terms of models, tools and strategies to keep up the process of intelligent configuration of destinations.
\end{abstract}

Keywords: Smart Tourism, Stakeholders, Business Models, Patterns

\section{INTRODUCTION}

Big data is an surfacing term that describe a large volume of structured, semi structured and unstructured data that has the likely to be mined for information and used in machine learning projects and other advanced analytics applications. Currently the insights from big data to uncover new opportunities for businesses. The progression of discovering and influential insights from large, complex, and unstructured datasets attracted the attention. The basic definition is "datasets which could not be captured, managed, and processed by general computers within an acceptable scope" [1]. More and more researchers and institutes are exploring the characteristics of big data in order to define it. These definitions always include the characteristics of volume (amount of data), velocity (speed of data in and out), and variety (range of data types and sources). Through the use of specific and sophisticated data mining techniques and analytics, within the Smart Tourism context, it is possible to provide a much better tourism experience, create contextualized openings based on tourist needs, correlate products and services with tourists, as a result providing better value to them in real time [4]. Performed through different tools for data collection, extraction, analysis and visualization, business analytics has recently captured the attention of both academics and practitioners by demonstrating its usefulness for exploitation of value from social media data, in spite of the huge amount of information provided, social media analytics can influence on a rich set of metadata (e.g., tags, user-expressed subjective opinions, ratings, user profile, etc.), prepared accessible by computer mediate social relations between users. Social media is now considered one of the main sources of Big Data generation in tourism, covering enormous opportunities for an added ancient decision-making process [5]. This give increase to a new idea, the so-called Social Big Data, defined as "process and method that are designed to provide insightful and related knowledge to any user or company from social media data sources when data sources can be characterised by their different format and stuffing, their very large size, and the online or stream generation of information".

Travellers depart different digital traces following on the Web via mobile technologies. From every traveller, large amounts of data are presented with reference to everything that is appropriate to any travel stage: prior to, during, and after travel [7]. Most of this data is of an external nature, in the form of Twitter or other social networking feeds. Appropriate to the large amounts of Predicting Tourist Demand Using Big Data available data stored in the cloud, analytics are needed in order to make sagacity of the information within the data. A potential tourist planning a trip, probably get more than a little help from the Internet are searching for inspiration, buying tickets, reserving accommodation, or searching attractions. Participants in the tourism industry are increasingly turning to big data to discover new ways to improve decision-making, opportunities, and overall performance for example, big data can be used to interconnect the dispersed information from different systems and then improve decision-making capability.

Four types of big data BI (Business Intelligence) that support business:

1. Prescriptive: This type of analysis reveals what actions should be taken. This is the most valuable kind of analysis and usually results in rules and recommendations for next steps.

2. Predictive: An analysis of likely scenarios of what might happen. The deliverables are usually a predictive forecast.

3. Diagnostic: A look at past performance to determine what happened and why. The result of the analysis is often an analytic dashboard. 
4. Descriptive: What is happening now based on incoming data. To mine the analytics, you typically use a real-time dashboard and/or email reports.

\section{BIG DATA ANALYTICS IN ACTION}

A. Prescriptive Analytics is valuable, but largely not used. Where big data analytics in general sheds light on a subject, prescriptive analytics gives you a laser-like focus to answer specific questions.

B. Predictive Analytics use big data to identify past patterns to predict the future. For example, some companies are using predictive analytics for sales lead scoring. Some companies have gone one step further use predictive analytics for the entire sales process, analyzing lead source, number of communications, types of communications, social media, documents, etc. Properly tuned predictive analytics can be used to support sales, marketing, or for other types of complex forecasts.

C. Diagnostic Analytics are used for discovery or to determine why something happened. For example, for a social media marketing campaign, you can use descriptive analytics to assess the number of posts, mentions, followers, fans, page views, reviews, pins, etc.

D. Descriptive Analytics or data mining are at the bottom of the big data value chain, but they can be valuable for uncovering patterns that offer insight. A simple example of descriptive analytics would be assessing credit risk; using past financial performance to predict a customer's likely financial performance. Descriptive analytics can be useful in the sales cycle, for example, to categorize customers by their likely product preferences and sales cycle.

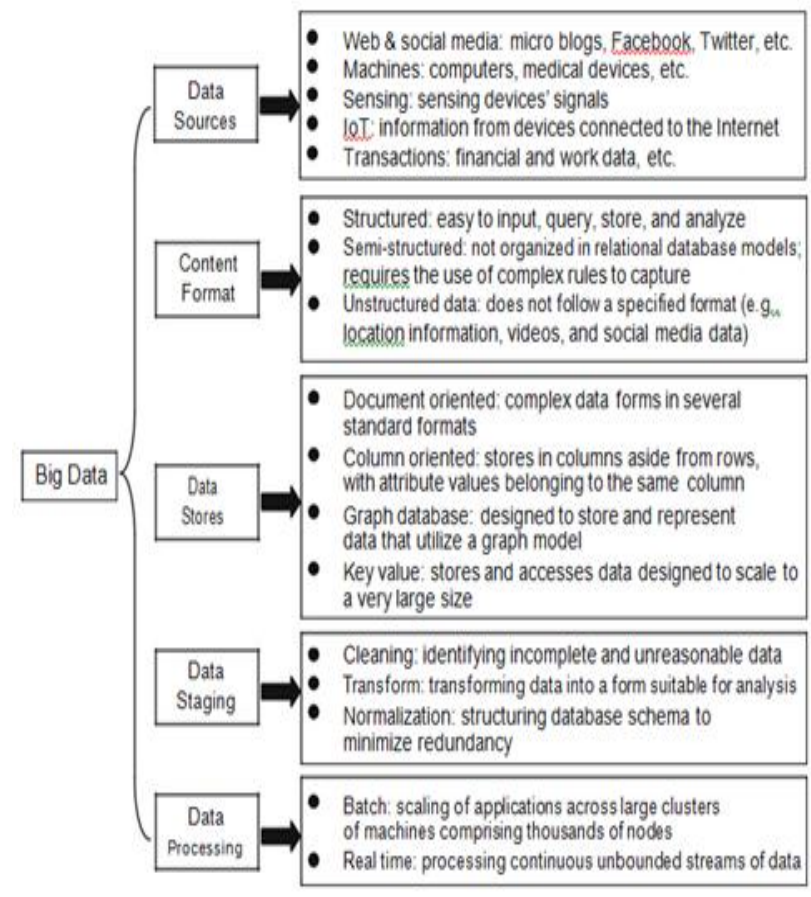

Fig. 1 Big data classification
Big data provides unprecedented insights into customers' decision-making processes by allowing companies to track and analyze shopping patterns, recommendations, purchasing behaviour, and other drivers that are known to influence sales.

\section{ADVANTAGES OF USING BIG DATA IN TOURISM}

Consumers and tourism product providers will see the benefits of using big data. Personalized marketing and targeted product designs are extremely powerful opportunities for both groups. It is crystal clear that big data can provide better, targeted and profitable services and products to consumers. Big data analysts can capture information of consumer interests from photos posted on Face book or other social networks[3] (e.g., a tourism provider could push information about local destinations or biking clubs. Earlier study on tourism have mostly been based on surveys or experts' views, which mean that they have taken samples from the population as a whole and do not have real data about all tourists. Tourism big data tried to introduce data based on real actions by all users instead of drawing information from survey samples [6]. A framework that incorporates big data produced by tourists them-selves (e.g., through mobile phones connecting to the telecom network or bank cards connecting to POS(point of sale) terminals that increases knowledge of the industry's target market into tourism demand forecasting. Tourism big data using innovative methods has advantages over traditional methodologies, as

A. Reliability: Big data are based on users' real actions, not on surveys. In other words, real actions have been analyzed rather than stated intentions or answers to questions. Taking all information sources together, it can be stated that big data increases the sample base on which conventional research tends to be based by several orders of magnitude [16]. The reliability of big data analysis allows us to consider all aspects of the information in order to provide comprehensive results instead of biased conclusions due to information loss in the sample data.

B. New Information Flows: Tourism big data is a type of information produced by tourists themselves; it enriches the knowledge of tourism businesses' target market and is very useful for analyzing the consumers' demand for different tourism products and ser-vices. Since tourism big data are structured and repositioned data, it is possible to crossreference them with other sources such as social media and open public data, whether these are sources currently in production or potential information sources that may be created or released in the future. The analysis of tourism big data can be contrasted with internal data Predicting Tourist Demand Using Big Data from each tourism business with a view to determining whether the supply of tourism products/ services in each area of a city.

C. Real-Time Data and Now Casting: One of the innovative uses of big data is now casting, that is, the use of real-time 
data to describe contemporaneous activities before official data sources are made available for example, [2] argued that real-time Google search queries are a good way to now cast (a report on current weather conditions) consumer activities, as the of that period correlation analysis obtained from the Google Correlate data reported values. There are many studies that have used structured search-engine data for tourism now casting and forecasting. Besides search engine queries, there are other types of real-time data streams that can be assembled and analyzed: for example, data on credit card purchases, the trucking and shipping of packages, and mobile phone usage are all useful bodies of information. Much of these data is becoming available on a near realtime basis, which can be used to predict the macro data that will be compiled at some point in the future.

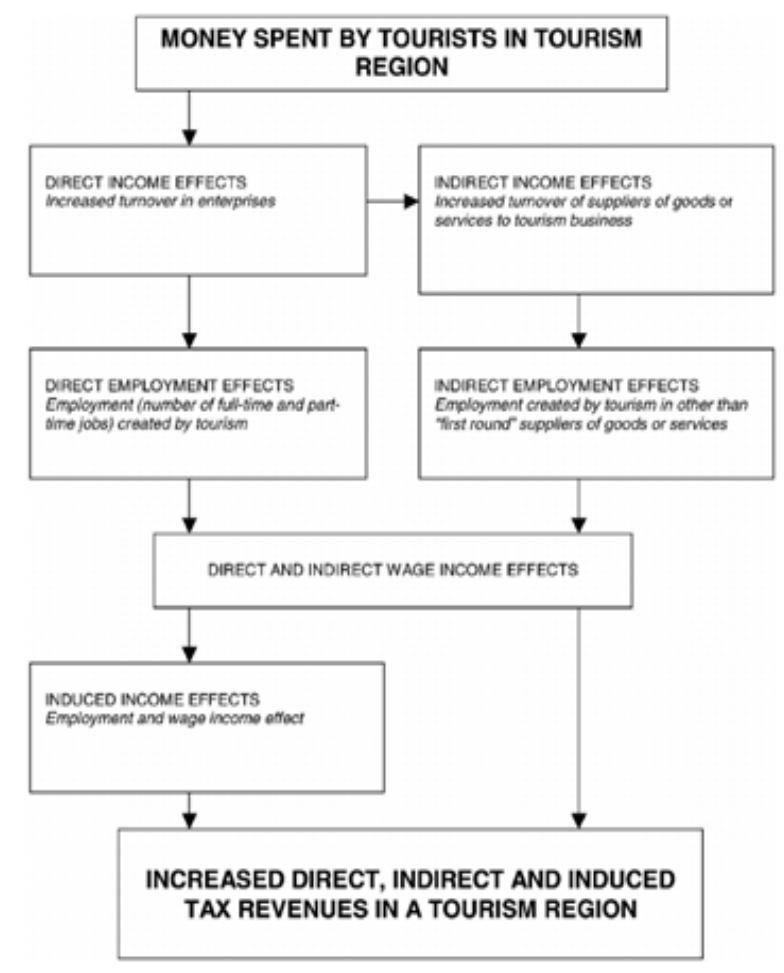

Fig. 2 The economic impacts of tourism

\section{BENEFITS OF BIG DATA TO TOURISM BUSINESSES}

Big data analysis is changing all sorts of industries, not just the usual retail, logistics, and high-tech industries [14]. It is also transforming the worlds of hospitality and travel since hospitality and tourism companies deal with a slew of user data covering all sorts of different information (e.g., flight confirmations or a customer's room preferences), and it creates all sorts of opportunities for correlating data to find otherwise unknown insights .In addition, there are some significant changes for big data because the cost of analytics platforms keeps dropping and employees are becoming more familiar with what big data can do. The tourism industry can learn a lot about consumer preferences and use this information and insight to build connections with individual travellers. Being able to offer travellers the right service or product at the right time is crucial. Without the right information and a very good targeting strategy, advertising will not result in any conversions and there will be no value. Travel is a fast-paced industry, and this drives the need for speedy data analytics and quick decisions. In tourism, any demand needs to be addressed instantly in order to remain relevant to travellers, and this is what makes big data so important. With the vigorous growth of the amount and applications of big data, traditional tourism data and methods are going to be interfacing with the novel data and methodologies.

A. Consumer Behaviour: Customer expectations and company business models created by technologies that are simultaneously disrupting established businesses and spawn new ones. Tourism big data show significant changes in the relationship between businesses and their customers. Big data holds many insights into customers' behaviour. The potentials created by big data is particularly acute in retail since industries and business processes can successfully exploit new communication channels, service delivery options, and unprecedented sources. Collecting, correlating, and analyzing tourism big data from customer interactions across channels is the key to transforming the customer experience from a nightmare to nirvana [13].The nexus between big data and machine learning in all its forms, including predictive analytics and even neural network deep learning, is the foundation of well informed, highly efficient, and deeply satisfying interactions that benefit both customers and businesses.

B. Feedback Mechanisms: Feedback in the tourism industry is important in the chase to identify customer preference and convey positive experiences. Solicit customer feedback is one of the most important elements in achieving high company growth and building a plan about better meeting customer needs. Feedback based on tourism big data from customers, employees, partners, suppliers, and communities has also improved the capabilities of big data analytics [5]. Data-driven business and consumer apps are the most common ways to collect feedback anytime and anywhere. The raise in meeting feedback using modern techniques has led to traditional feedback marketing being gradually emplaced by commercial messages which are quick, unique, focused, and personal.

One of the application of the feedback mechanisms applied by the providers of tourism-related goods and services is price adjustment, in which vary in travel demand obtain from big data analysis and forecasting can make available useful information for quick and effective cost adjustment. Machine learning is one of the key technical methods used in the tourism industry to construct the feedback mechanism between customers and tour operators. Customer feedback mechanisms must be well designed and complete to deliver actionable data in a timely fashion and acted upon immediately [9]. Timely and reliable tourism big data can provide a rich description of customers and potential 
customers and subsequently lead to marketing efforts with advertising targeted toward the most fruitful channels.

\section{CAPTURING BIG DATA FOR TOURISM FORECASTING}

Companies that efficiently confine and implement big data strategy grow a viable advantage because the technology required to process big data is a barrier for many business users because of its complexity and cost. There are several steps in the process of capturing big data before we use it [6].

A. Objective: The first step is the objective of using big data, which is to make sure that business benefits are derived from it [12]. When we capture big data, we should be able to access it and know what is available and determine where the business value lies. In other words, we should know the capability of big data and exactly what we are looking for and look to see what its values are. It is important to set specific business goals rather than just dealing with the big data itself.

B. Visualizing Big Data: The second step is to make the big data visible to users within a company/ organization [10]. This will enable tourism forecasters to determine the optimal quantities of a product and to adjust logistical processes to maximize efficiency. The purpose of data visualization is to find the ways in which data could be effectively collected from different sources (visual and nonvisual) and presented so that users could easily understand them. This will also help forecasters to better utilize big data in fulfilling their forecasting tasks.

C. Structuring Big Data: The third step is to structure the unstructured data. This means to arrange big data according to traditional data length and format so that they can be fitted neatly into rows and columns in the spreadsheet. Structured data generally resides in a relational database and, as a result, is sometimes called relational data.

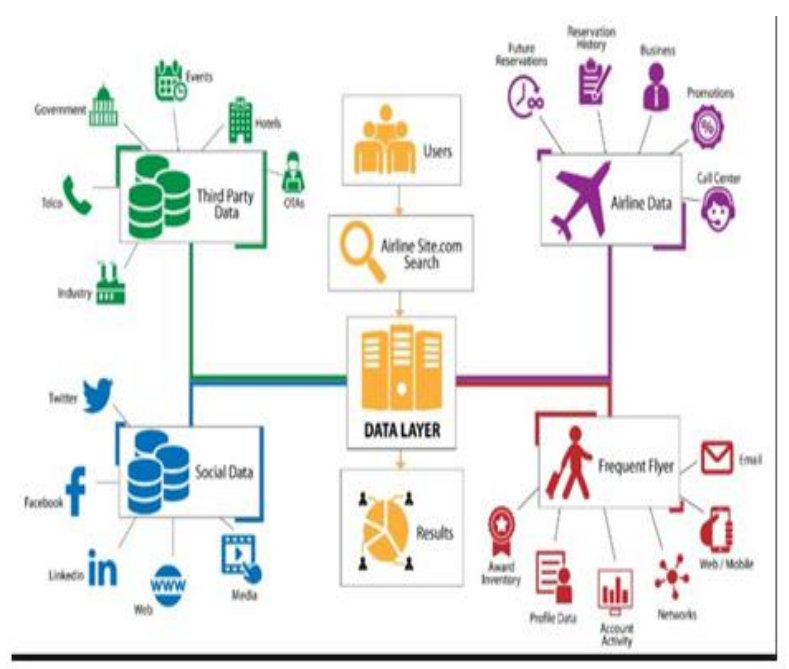

Fig. 3 Capturing Big Data for Tourism Forecasting

\section{AFRAMEWORK FOR PREDICTING TOURISM DEMAND USING BIG DATA}

The big data can assist the progress of forecasts can analyze and discover hidden patterns and that predictions can be superior during data-driven decision-making used in tourism demand forecasting [3]. In conventional forecasting method for tourism require forecasting with big data, the major problem is that the traditional forecasting tools cannot handle the size, speed, and complexity inherent in big data even when it has been structured. In order to apply a traditional forecasting method to big data, to simplify the structured big data. One of the solutions is to minimize the big data and get the most important information in a suitable format that can be easily applied to the traditional forecasting model. Factor models are the most common and popular statistical and data mining technique used for big data forecasting, neural networks and Bayesian models are two other popular choices.

A. Mixed Frequency Model with Big Data: Aggregated Google data for Hong Kong's tourism demand forecasting and suggested that Google Trends' data about a destination may be useful in predicting visits to that destination[14]. The studies always aggregate weekly observations in order to make the datasets appropriate for the traditional forecasting methods [4]. A novel forecasting method, the mixed-data sampling (MIDAS) approach to fully utilize the high frequency search engine data. Another mixed frequency model is the mixed frequency VAR model, which treats low frequency data as high frequency data with missing data and then uses the state space model to deal with it.

\section{B. Factor Model and Fore Casting Combination}

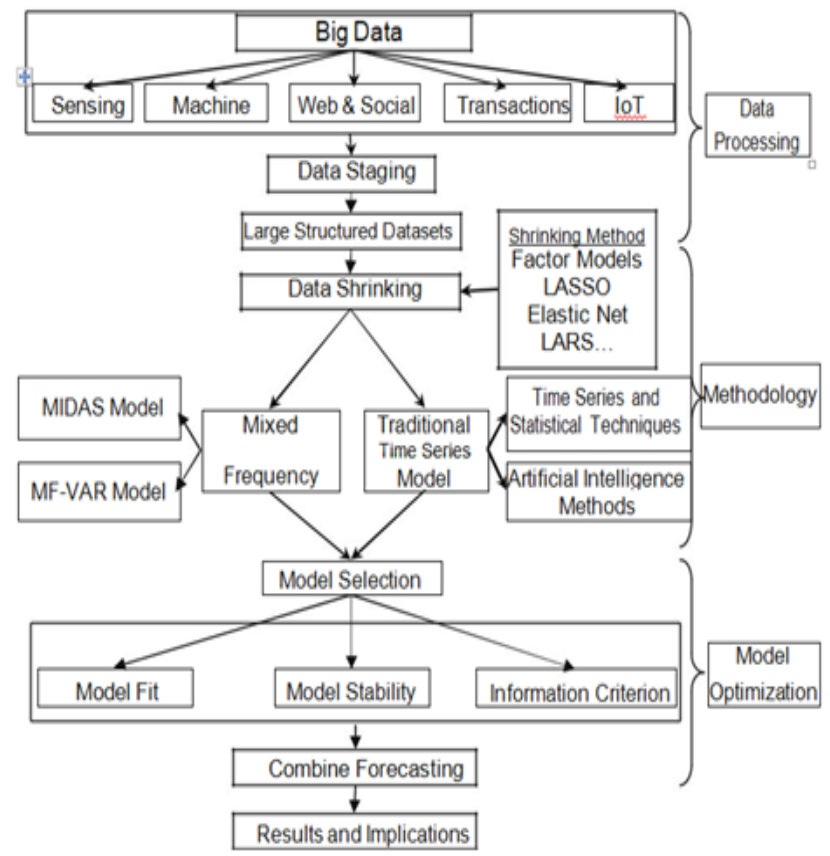

Fig. 4 The framework of tourism forecasting with big data 
To forecast the low frequency series (such as tourism demand) using high frequency data is to combine the shrinkage method with the mixed frequency models [7]. Some studies used the mixed frequency model with factor high frequency data to forecast the macroeconomic indicators and obtained improved forecasting performance. Fig.4display the framework of tourism forecasting with big data. There are three important steps: (1) data exploration, which is the data processing that prepares the proper data for the model; (2) use modelling techniques to predict user behaviour on the basis of their previous business transactions and preferences; (3) optimize the forecast results and decrease the forecast failure risk by model selection and combination forecasting [8].

\section{CONCLUSION}

Big data is a social, cultural, technological, and ethical experience that is not all good, all bad, or consistently neutral. With the propagation and explosive increase in the application of big data, it has become a common tool in corporate decisions and a number of new social risks have arisen. At the same time, as data technologies become more persistent, there are also privacy concern and the possible for the exploitation and misuse of big data. The use of tourism big data for forecasting has some able to be seen and covered pitfalls. There are questions about the constancy of the analysis and interpretation when the tools and techniques that we used in analyzing the big data have changed the patterns that emerged from big data analysis or forecasting be broad, information and isolation be controlled everything is systematically counted and recorded.

\section{REFERENCES}

[1] R. Akerkar, Big data computing, $1^{\text {st }}$ Edition Boca Raton, FL: CRC Press, 2013.
[2] C. Artola, F. Pinto and P.D. Pedraza, "Can internet searches forecast tourism inflows?", International Journal of Manpower, Vol. 36, No.1, pp.103-116, 2015.

[3] J. Bai, and N.G. Serena, "Confidence intervals for diffusion index forecasts and inference for factor-Augmented regressions", Journal of Econometrica, Vol.74, No.4, pp.1133-1150, 2006.

[4] J. Bai and N.G. Serena, "Forecasting economic time series using targeted predictors", Journal of Econometrics, Vol. 146, No. 2, pp.304-317, 2008.

[5] P. Bajari, D. Nekipelov, S. P. Ryan and M. Yang, "Machine learning methods for demand estimation", Journal of American Economic Review, Vol. 105,No. 5, pp. 481-485,2015.

[6] M. Banbura and G. Reunstler, "A look into the factor model black box: Publication lags and the role of hard and soft data in forecasting GDP”, International Journal of Forecasting, Vol.27, No. 2, pp.333346, 2011.

[7] P. F. Bangwayo-Skeete and R.W Skeete, "Can Google data improve the forecasting performance of tourist arrivals Mixed-data sampling approach", Tourism Management Journal, Vol. 46, pp. 454464,2015 .

[8] P. J Benckendorff, P. J Sheldon and D. R Fesenmaier, Tourism information technology, $2^{\text {nd }}$ edition, Wallingford: Cab-International, 2014.

[9] M. Bessec, "Short-term forecasts of French GDP: A dynamic factor model with targeted predictors", Journal of Forecasting, Vol. 32,No. 6 , pp. 500-511, 2013.

[10] J. T Coshall and R.Charles worth, "A management orientated approach to combination forecasting of tourism demand", Tourism Management Journal, Vol.32, No. 4, pp. 759-769,2011.

[11] A. De Mauro, M. Greco and Grimaldi, "What is big data? A consensual definition and a review of key research topics", Inproc. AIP, 2011, paper 1644, pp. 97-104.

[12] M. DeutschGranger, and T. Tera"svirta, "The combination of forecasts using changing weights", International Journal of Forecasting, Vol. 10, No. 1, pp.47-57, 1994.

[13] M. Fuchs, W. Heopken and, M. Lexhagen, "Big data analytics for knowledge generation in tourism destinations-A case from Sweden", Journal of Destination Marketing and Management, Vol.3, No. 4, pp.198-209, 2014

[14] M. Hallin and R. Liska, "Dynamic factors in the presence of blocks", Journal of Econometrics, Vol. 163, No. 1, pp. 29-41, 2011.

[15] W.Q. Meeker and Y. Hong, Reliability meets big data: Opportunities and challenges. $2^{\text {nd }}$ Edition, Quality Engineering, 2014.

[16] A. McAfee, Brynjolfsson, E. Davenport, T. H. Patil and D. Barton, "Big data: The management revolution", Harvard Business Review, Vol.90, No. 10, pp. 61-67, 2012. 